RICHARD H. CLARIDA

Yale University

BENJAMIN M. FRIEDMAN

Harvard University

\title{
Why Have Short-Term Interest Rates Been So High?
}

THE most visible and persistent feature of the U.S. financial markets thus far during the 1980 s has been high interest rates. Observed nominal interest rates on most instruments traded in the U.S. debt markets have set record highs twice since 1980. Perhaps more important, "real" interest rates, in the sense of observed nominal rates less a presumed expectation of future price inflation, have been unprecedentedly high as well. During the past few years nominal interest rates first rose to levels far above the prevailing inflation rate, and more recently the decline in nominal interest rates has lagged well behind the slackening pace of inflation. Especially for instruments of short maturity, for which inferences about expectations of inflation in the distant future are not necessary, these high nominal interest rates have clearly corresponded to high real rates as well.

Although the rough dimensions of this development are broadly familiar, it may be helpful to recall just how sizable these interest rate movements have been. The three-month U.S. Treasury bill rate, for example, was 11.60 percent on average during the fifteen calendar quarters beginning in 1979:4 (when the Federal Reserve System announced its new monetary policy) and extending through mid-year 1983.

We are grateful to Diane Coyle for research assistance and helpful suggestions, to the National Science Foundation and the Alfred P. Sloan Foundation for research support, and to members of the Brookings Panel for comments on early drafts of this paper. 
During the immediately preceding fifteen quarters the average threemonth bill rate was only 6.55 percent. Not a single quarter's value during the more recent period was as low as the mean for the previous period, and not a single quarter's value from the previous period was as high as the more recent mean. The analogous contrast with still earlier periods is even greater. The three-month bill rate averaged 6.12 percent during the 1970s (except for 1979:4), and averaged 3.45 percent from the end of the Korean War through the 1960s. Long-term interest rates have shown roughly similar patterns.

Comparisons with the corresponding implied real interest rates show, if anything, even sharper contrasts. On the basis of price inflation as measured by the change in the GNP deflator, the real three-month Treasury bill rate was 4.60 percent on average during 1979:4-1983:2, but slightly negative, at -0.3 percent, on average during 1976:1-1979:3 . Given the state of and prospects for the U.S. economy since 1980, market participants probably anticipated at least part of the cyclical slowing, and then the continuing slower rate, of inflation. Hence this change from a negative to a sharply positive implied real interest rate probably corresponds, at least roughly, to a rise in the unobservable real short-term interest rate perceived by market participants. Analogous calculations for long-term interest rates show a similar steep rise in the implied real rate; what inflation rate is appropriate in this case is less clear, however, so that inferences about the relevant real long-term rate are less reliable.

The persistence of such pervasively high interest rate levels in the United States has not merely attracted attention as a financial phenomenon notable in its own right, but has also created concerns about its likely consequences for nonfinancial economic activity. The most frequently expressed concern has been that high interest rates, including especially high real rates, will so discourage overall economic activity as to cause the business recovery that began in late 1982 to "abort" well before the economy returns to full utilization of its labor and capital resources. No doubt a prominent source of this concern is the recollection of the role that high interest rates played in making the twelve-month recovery from the 1980 recession the shortest U.S. business recovery in six decades. An additional worry, equally or even more important for the economy's longer-run prospects, is that high interest rate levels will discourage interest-sensitive investment in business and residential 
capital, leaving an expansion largely dominated by consumer and government military spending.

The objective of this paper is to gain some understanding of the prevailing high level of U.S. short-term interest rates by framing and attempting to answer two questions: Have short-term interest rates been "too high"- that is, higher than would have been expected given the relevant historical relations between interest rates and other key aspects of macroeconomic activity? If so, why? In other words, is it possible to explain whatever has been unusual about the recent behavior of shortterm interest rates in terms of familiar macroeconomic concepts like aggregate demand, aggregate supply, demand for money, and so on?

The basic framework for addressing questions like these must therefore be some representation of the relevant historical relations. Useful representations for this purpose may be simple or complicated and may range from unrestricted correlations to highly detailed models with elaborate structural restrictions. The strategy in this paper is to forecast short-term interest rates using a small "structural" macroeconometric model developed and estimated through 1976:2 in a previous BPEA paper by Friedman, and then to examine the model's forecasts and forecast errors. ${ }^{1,2}$

The analysis first focuses on the model's average short-term interest rate forecasts and forecast errors during 1976:3-1979:3, and again during 1979:4-1983:2. This comparison between the recent behavior of shortterm interest rates and the model's postsample forecasts sheds light on whether rates have been "too high" given the historical correlations summarized by the model. A decomposition of the model's forecast errors into respective elements due to the disturbance terms associated with individual structural equations then leads to conclusions about the relative contributions of various sources of the high short-term interest rates prevailing in the more recent period.

Any such analysis depends, of course, on the assumption that the model's slope parameters have remained unchanged during the post-

1. Benjamin M. Friedman, "The Inefficiency of Short-Run Monetary Targets for Monetary Policy," BPEA, 2:1977, pp. 293-335.

2. In another paper the authors take the opposite approach, using an unrestricted vector autoregression to summarize the relevant historical correlations. See Richard $\mathrm{H}$. Clarida and Benjamin M. Friedman, "The Behavior of U.S. Short-Term Interest Rates since October 1979: A Statistical Analysis" (Harvard University, 1983). The results of that analysis are consistent with those reported here. 
sample forecast period under examination. This assumption is especially important for the error decompositions underlying the paper's conclusions about the reasons for the observed high level of short-term interest rates. The analysis compares the actual path of short-term interest rates to the path that would have been consistent with historical relations if they had remained as they were in the past. By contrast, an announced and credible change of policy regime like that instituted by the Federal Reserve System in October 1979 can change any or all parameters of a model like the one employed here. If such a break did in fact occur-and there is evidence that one did-it would then not be possible to recover the structural disturbances from the corresponding forecast errors using the model's historically estimated coefficients. The importance of this argument is an empirical issue, and in the final section of the paper we present evidence bearing on it in the context of the exercise reported here.

The analysis reveals that short-term interest rates since October 1979 have been "too high" in the sense discussed above and that the familiar story of relatively little money for the prevailing levels of economic activity (in particular, the slow growth of real money balances due to the combination of slow growth of nominal money supply and sluggish deceleration of price inflation) goes a long way toward explaining why this has been so. In contrast to earlier postsample periods, the model substantially underpredicts short-term interest rates on average during 1979:4-1983:2. Decomposition of the model's forecast errors shows that unexpectedly slow growth in money supply and unexpectedly rapid price inflation are the largest factors accounting for this underprediction. The evidence indicating a shift in the model's slope parameters warrants caution in interpreting the latter results, however; such results are perhaps more suggestive as an aid to intuition than they are directly descriptive.

\section{The Model and Its Interest Rate Forecasts}

Friedman's earlier model includes empirical estimates for relations describing aggregate demand, aggregate supply, money demand, money 
supply, the term structure of interest rates, and a nominal income identity. ${ }^{3}$ The model was estimated by Fair's method for simultaneous equations with lagged dependent variables and serially correlated disturbances, using quarterly U.S. data spanning 1961:1-1976:2. ${ }^{4}$ Friedman called this six-equation model the Pirandello model.

The revised equations of the model and empirical estimates for the 1961:1-1976:2 sample period are as follows. ${ }^{5}$

Aggregate demand:

$$
\begin{aligned}
\Delta X_{t}= & 0.0057-0.1082 \Delta r_{L t}+0.1274 \Delta E_{t} \\
& (4.2) \quad(-2.9) \\
& -0.0611 \Delta I_{t-1}+0.4839 \Delta X_{t-1} \\
& (-1.9) \quad(5.4) \\
\bar{R}^{2}= & 0.58, \text { standard error }=0.00767, \text { rho }=-0.4
\end{aligned}
$$

Aggregate supply:

$$
\begin{aligned}
\Delta P_{t}= & 0.0929 \Delta X_{t-1}+0.0626 \Delta I_{t-1}+0.8371 \Delta P_{t-1} \\
& (3.6) \quad(4.5) \quad(22.9) \\
& \bar{R}^{2}=0.89, \text { standard error }=0.00336, \text { rho }=-0.1
\end{aligned}
$$

Money demand:

$$
\begin{aligned}
\Delta(M-P)_{t}= & 0.0970 \Delta X_{t}-0.0437 \Delta r_{S t}+0.9583 \Delta(M-P)_{t-1} \\
& (1.4) \quad(-3.8) \\
\bar{R}^{2}= & 0.57, \text { standard error }=0.00725, \text { rho }=-0.6
\end{aligned}
$$

3. Friedman, "The Inefficiency of Short-Run Monetary Targets." For a comparative analysis of the original model's performance, see Kevin Maloney, Lawrence H. Meyer, and Michael Smirlock, "A Comparison of Small Income Expenditure and Monetarist Econometric Models," in Lawrence H. Meyer, ed., A Comparison of the Predictive Performance of Small Macroeconometric Models, vol. 2, Working Paper Series (Washington University, Department of Economics, 1983), pp. 1-26.

4. Ray C. Fair, "The Estimation of Simultaneous Equation Models with Lagged Endogenous Variables and First Order Serially Correlated Errors,' Econometrica, vol. 38 (May 1970), pp. 507-16. Because of problems encountered in the estimation, the money supply equation was estimated by ordinary least squares in the original model.

5. All variables are in logarithms. Predetermined variables are $E, I, L, R, r_{D}$, and $S$. The numbers in parentheses are $t$-statistics. 
Money supply:

$$
\begin{aligned}
\Delta M_{t}= & 0.0037+0.2513 \Delta R_{t}+0.0182 \Delta r_{S t} \\
& (2.5) \quad(2.4) \\
& -0.0348 \Delta r_{D t}+0.6879 \Delta M_{t-1} \\
& (-1.9) \quad(6.9) \\
\bar{R}^{2}= & 0.48, \text { standard error }=0.00475, \text { rho }=-0.2
\end{aligned}
$$

Term structure of interest rates:

$$
\begin{gathered}
r_{L t}=0.0334+0.1145 r_{S t}-0.0320 r_{S, t-1} \\
\begin{array}{c}
(0.8) \quad(0.7) \quad(-0.2) \\
+0.1319 \Delta(L-S)_{t-1}+0.9215 r_{L, t-1} \\
\quad(2.0)
\end{array} \\
\bar{R}^{2}=0.99, \text { standard error }=0.021, \text { rho }=0.4
\end{gathered}
$$

Nominal income identity:

$$
\Delta Y_{t}=\Delta X_{t}+\Delta P_{t},
$$

where

$$
\begin{aligned}
E & =\text { high-employment federal expenditures } \\
I & =\text { import price deflator } \\
L & =\text { outstanding long-term federal debt } \\
M & =\text { money stock (M1) } \\
P & =\text { GNP price deflator } \\
R & =\text { stock of nonborrowed reserves } \\
r_{D} & =\text { discount rate } \\
r_{L} & =\text { Baa corporate bond rate } \\
r_{S} & =\text { three-month Treasury bill rate } \\
S & =\text { outstanding short-term federal debt } \\
X & =\text { real GNP } \\
Y & =\text { nominal GNP. }
\end{aligned}
$$

Apart from revisions in the data, these estimates differ from those presented in the previous $B P E A$ paper in two ways. First, while the money demand equation retains the original specification, money is defined here as the narrow M1 money stock. (It was M2 in the original 
version. $)^{6}$ Second, this change in the definition of the money stock variable requires a slightly different specification of the money supply equation, involving the introduction of an intercept and the discount rate. ${ }^{7}$ In all other respects, the model's definitions and specifications are exactly the same as in the original.

There is no point in repeating here the detailed discussion of each equation presented with the original estimates in Friedman's 1977 paper, but a few summary comments may be helpful. The aggregate demand equation includes an interest rate, or IS curve, effect (here based on a nominal long-term interest rate), a fiscal policy effect, and a terms-oftrade effect. ${ }^{8}$ The aggregate supply equation relates price setting to real economic activity and also to the terms of trade. The money demand equation has the standard real LM curve specification. The money supply equation combines a nonborrowed reserves multiplier effect with a borrowed reserves response associated with the discount rate and an excess reserves response associated with the short-term market interest rate. The term structure equation, which provides a link between the long-term interest rate in the aggregate demand equation and the shortterm interest rate in the money demand and money supply equations, combines a form of the standard expectations hypothesis with a debtmanagement policy effect. ${ }^{9}$ The nominal income identity is straightforward.

For convenience, all equations of the model are assumed to be linear in logarithms, and no variable is lagged more than once. Hence the model is a simple linear first-order difference equation system. As applied here, the model determines six variables: the growth rates of real and nominal income, prices and the money stock, and short- and long-term interest rates. Exogenous variables include fiscal policy (high-employment gov-

6. At that time it appeared that the Federal Reserve System was moving toward an M2 orientation for monetary policy. Subsequent experience showed the primacy of M1, however.

7. In addition, the money supply equation is estimated here using Fair's method; see note 4 . The inclusion of the discount rate may make it appear to be too easy for the model to forecast interest rates, but the steady-state coefficient relating the logarithm of the discount rate to the logarithm of the Treasury bill rate is only 0.06 .

8. See the text below for a discussion of real interest rates in the IS curve and for an estimated example.

9. In the reestimated term-structure equation the coefficients on the two short-term interest rate terms are no longer significant individually but are highly significant jointly; the $F$-statistic for a test of the null hypothesis that both coefficients are zero is 21.26 . 
ernment expenditures), monetary policy (nonborrowed reserves and the discount rate), debt-management policy (the maturity of outstanding government debt), and the dollar price of imports. The model's compactness and simplicity result from the imposition of many restrictions on the data. The advantage of such restrictions is not just convenience but the ease with which it is possible to carry out analytical exercises such as the ones reported below.

The top panel of table 1 shows the model's quarter-by-quarter performance in forecasting short-term interest rates from 1976:3 to 1979:3 - the first thirteen quarters beyond the end of the sample period. These forecasts are based on a dynamic simulation in which, after the first postsample quarter, the forecast of each variable relies on the model's forecast of all endogenous variables in the previous period. Although the short-term interest rate variable generated by the model is a logarithm, for convenience the table reports values converted to natural units stated in percentage points.

The model correctly forecasts the general upward trend of short-term interest rates during this thirteen-quarter period, though hardly without errors. The forecast error has a mean of 0.30 percentage point-that is, a small overprediction-and a root mean square of 0.70 point. For a thirteen-quarter beyond-sample dynamic forecast, with a model designed with compactness and simplicity as top priorities, this performance is far from poor. More specifically, it suggests that the structural restrictions that the model places on the historical correlations among the included variables represent an efficient summary of the data and also capture the essential features of the correlations among variables relevant for forecasting.

The bottom panel of the table shows an analogous account of the model's performance for 1979:4-1983:2, based on a reestimation of the model using 1961:1-1979:3 data. An appendix to this paper shows the reestimated equations. As above, the forecasts are based on a dynamic simulation relying, except for the first quarter, on the model's own forecast of all endogenous variables. The results of Chow tests do not indicate evidence of a break after 1976:2 for any of the model's five estimated equations, so that in principle there is no need to use a reestimated model for the second forecast period. ${ }^{10}$ Nevertheless, the two sets of forecasts and forecast errors are more directly comparable if

10. The $F$-statistics are reported in the first column of table 5 below. 
Table 1. Short-Term Interest Rate Forecasts and Forecast Errors, 1976:3 through 1983:2

Percent

\begin{tabular}{|c|c|c|c|}
\hline $\begin{array}{c}\text { Quarter and } \\
\text { mean }\end{array}$ & Forecast & Actual & Error \\
\hline $1976: 3$ & 5.39 & 5.17 & 0.22 \\
\hline 4 & 5.46 & 4.70 & 0.76 \\
\hline 1977:1 & 5.58 & 4.62 & 0.96 \\
\hline 2 & 6.11 & 4.83 & 1.28 \\
\hline 3 & 6.36 & 5.47 & 0.89 \\
\hline 4 & 6.79 & 6.14 & 0.65 \\
\hline 1978:1 & 6.87 & 6.41 & 0.46 \\
\hline 2 & 7.11 & 6.48 & 0.63 \\
\hline 3 & 7.55 & 7.32 & 0.24 \\
\hline 4 & 8.41 & 8.68 & -0.27 \\
\hline 1979:1 & 8.62 & 9.36 & -0.74 \\
\hline 2 & 8.80 & 9.37 & -0.58 \\
\hline 3 & 9.06 & 9.63 & -0.58 \\
\hline Mean & 7.08 & 6.78 & 0.30 \\
\hline 1979:4 & 10.68 & 11.80 & -1.12 \\
\hline 1980:1 & 12.21 & 13.46 & -1.25 \\
\hline 2 & 11.61 & 10.05 & 1.56 \\
\hline 3 & 11.04 & 9.23 & 1.81 \\
\hline 4 & 11.65 & 13.71 & -2.06 \\
\hline 1981:1 & 11.97 & 14.37 & -2.40 \\
\hline 2 & 12.88 & 14.83 & -1.95 \\
\hline 3 & 12.47 & 15.09 & -2.62 \\
\hline 4 & 11.41 & 12.02 & -0.61 \\
\hline 1982:1 & 11.48 & 12.90 & -1.41 \\
\hline 2 & 11.46 & 12.36 & -0.90 \\
\hline 3 & 10.46 & 9.71 & 0.76 \\
\hline 4 & 9.95 & 7.94 & 2.01 \\
\hline 1983:1 & 6.95 & 8.08 & -1.13 \\
\hline 2 & 6.95 & 8.42 & -1.47 \\
\hline Mean & 10.88 & 11.60 & -0.72 \\
\hline
\end{tabular}

Sources: The top panel is from text equations 1 through 6 estimated over 1961:1-1976:2; the bottom panel, from the same equations estimated over 1961:1-1979:3 and shown in the appendix. Data are from the Board of Governors of the Federal Reserve System.

each refers to a sequence of quarters immediately following the sample period of the model used to generate it. ${ }^{11}$

As judged solely by the forecast mean, the model does a fairly adequate job of forecasting the average upward shift in the short-term interest rate

11. In any case, the choice of the equations shown in the text versus those in the appendix does not matter much for the interest rate forecast results shown here. An analogous simulation for 1979:4-1983:2, based on the model estimated only through 1976:2, generated mean forecasts for the Treasury bill rate of 10.91 percent. Even the quarter-by-quarter patterns of the two sets of interest rate forecasts were closely similar. 
in this second postsample period. In contrast to the 0.30 percent mean overprediction of the bill rate in the earlier period, the mean forecast error in the more recent period is -0.72 percent, an underprediction. This underprediction is small, however, in comparison with the large change in the average level of the bill rate between the two periods. Hence the model, with its conventional determination of the short-term interest rate by the equation of money supply and money demand, also performs fairly well in forecasting the sharply higher mean level of the Treasury bill rate in the more recent period. Taken at face value, these results suggest that, on average, short-term interest rates since October 1979 have been not very much higher than would have been consistent with previous historical relations, given the policy and nonpolicy determinants of nonfinancial economic activity and hence money demand, as well as money supply, as summarized in the model.

Closer examination reveals reasons for rejecting this initial impression, however. An inspection of the underlying quarter-by-quarter pattern indicates that this relatively successful prediction of the bill rate's mean over the more recent fifteen-quarter forecast period masks some large errors. The model underpredicts the rate in all quarters except 1980:2-1980:3, when formal credit controls were in effect, and 1982:3$1982: 4$, when the rate suddenly plummeted to a level that soon proved transitory. The mean forecast error for the remaining eleven quarters is -1.54 percentage points. Although the actual Treasury bill rate exceeded 13 percent in five of these quarters and 15 percent in 1981:3, the model's peak forecast is only 12.88 percent. The root mean square error for 1979:4-1983:2 is 1.64 percentage points, more than double the 0.70 point for 1976:3-1979:3.

More important, simply obtaining a correct answer (here, a nearly correct answer) is not the end of the story. It is also important to be right for the right reasons. Decomposition of the forecast errors reported in table 1 to trace these errors to disturbances in the model's structural equations shows that the model for 1976:3-1979:3 is right for approximately the right reasons. The model's performance in forecasting shortterm interest rates since October 1979, however, turns out to be (nearly) right for the wrong reasons.

\section{Decomposition of the Forecast Errors}

Given the historically estimated coefficients of a linear model like that shown in equations 1 through 6 , it is straightforward to recover the 
contribution made by each equation's structural disturbance toward explaining the errors in forecasting each of the model's endogenous variables. If $v_{i t}$ is the dynamic forecast error for the $i$ th endogenous variable in period $t$, and $u_{j s}$ is the additive structural disturbance to the $j$ th equation in period $s$, then equations 1 through 6 imply the system of linear difference equations,

$$
\begin{aligned}
v_{1 t} & =u_{1 t}+\beta_{13} v_{1, t-1}+\beta_{12} v_{5 t}, \\
v_{2 t} & =u_{2 t}+\beta_{22} v_{1, t-1}+\beta_{23} v_{2, t-1}, \\
\beta_{34} v_{3 t} & =-u_{3 t}-\beta_{32} v_{1 t}-v_{2 t}+\beta_{33} v_{4 t}+v_{4 t}-\beta_{33} v_{4, t-1}, \\
v_{4 t} & =u_{4 t}+\beta_{43} v_{4, t-1}+\beta_{42} v_{3 t}, \\
v_{5 t} & =u_{5 t}+\beta_{52} v_{3 t}+\beta_{53} v_{3, t-1}+\beta_{54} \mathrm{v}_{5, t-1} \\
v_{6 t} & =v_{1 t}+v_{2 t},
\end{aligned}
$$

where the $\beta$ values are the estimated coefficients shown in equations 1 through 5. Since the $v_{i t}$ are known (and in particular are identically zero before 1976:2 or 1979:3 in the two simulations, respectively), it is possible to solve this system of equations recursively to recover the sequence of structural disturbances corresponding to each of the five estimated equations. The structural model is dynamic, so that the forecast errors, $v_{i t}$, are in general linear functions of current as well as past structural disturbances, $u_{j s}$.

Although the model is estimated in first differences, it is also straightforward to recover the contribution made by each equation's structural disturbances toward explaining the errors in forecasting the log level of the short-term interest rate (or any of the model's other five endogenous variables). The identity,

$$
\ln r_{S t}=\ln r_{S, t-1}+\Delta \ln r_{S t}
$$

implies

$$
\ln r_{S t}-\ln \hat{r}_{S t}=\sum_{\tau=1976: 2}^{t} \Delta \ln r_{S \tau}-\Delta \ln \hat{r}_{S \tau}=\sum_{\tau=1976: 2}^{t} v_{3 \tau},
$$

where the circumflex indicates a forecast value. In other words, the forecast error of the log level of the short-term rate equals the sum of past forecast errors of the difference of the log of the short-term rate.

This procedure exactly decomposes the log error in forecasting each interest rate level into contributions representing the model's five structural disturbances. However, it is convenient to think about interest 
rates in natural units rather than in logarithms. Because the log operator is nonlinear, the decomposition of the log errors does not correspond exactly to a decomposition of the natural-unit errors. The discussion proceeds as if the correspondence were exact, so that a disturbance contributing, say, $Z$ percent of the log error is likewise assumed to contribute $Z$ percent of the error stated in natural units.

In general, positive disturbances to aggregate demand, $u_{1}$, price setting, $u_{2}$, and money demand, $u_{3}$, all cause underpredictions of the short-term interest rate, while positive disturbances to money supply, $u_{4}$, and the yield-spread relation, $u_{5}$, both cause overpredictions. The signs of these effects are easy to explain in terms of the determination of the short-term rate in the equations expressing money demand and money supply. Because of the dependence of the demand for real balances on real economic activity, a positive disturbance to aggregate demand or to the money demand function itself increases the demand for real balances, and hence nominal money demand given prices. Similarly, a positive disturbance to prices raises money demand given the factors determining the demand for real balances. A positive disturbance to the nominal money supply has the reverse effect. Finally, a positive disturbance to the yield-spread relation reduces the demand for money by diminishing aggregate demand through the effect of the longterm interest rate in the IS curve.

Table 2 presents the results of applying the method described above to decompose the short-term interest rate forecast errors shown in table 1 into components representing the separate contributions of the disturbances to the model's structural equations. As the discussion has already noted, the model's mean errors in forecasting the Treasury bill rate for 1976:3-1979:3 and 1979:4-1983:2 are 0.30 percentage point and -0.72 point, respectively. The two columns of the table show a decomposition of these mean forecast errors into five components, corresponding to the model's five stochastic relations.

For 1976:3-1979:3 the dominant source of the small mean overprediction was a positive disturbance to money supply growth that lowered the actual bill rate (but not the predicted rate) by 0.61 percentage point on average. A negative disturbance to the growth of money demand added another 0.21 point to this average error, but a positive disturbance to price inflation simultaneously offset -0.51 point of it. The disturbances to the growth of aggregate demand and to the yield-spread relation were both trivially small on average during this period. The 0.30 
Table 2. Decomposition of Short-Term Interest Rate Forecast Errors, 1976:3-1983:2 ${ }^{\mathrm{a}}$ Percent

\begin{tabular}{lcc}
\hline $\begin{array}{c}\text { Error and } \\
\text { decomposition }\end{array}$ & $\begin{array}{c}\text { Mean, } \\
\text { 1976:3-1979:3 }\end{array}$ & $\begin{array}{c}\text { Mean, } \\
\text { 1979:4-1983:2 }\end{array}$ \\
\hline Forecast & 7.08 & 10.88 \\
Actual & 6.78 & 11.60 \\
Error source & 0.30 & -0.72 \\
Aggregate demand & -0.05 & 0.63 \\
Aggregate supply & -0.51 & -3.98 \\
Money demand & 0.21 & 0.14 \\
Money supply & 0.61 & -2.69 \\
Term structure & 0.03 & 5.17 \\
\hline
\end{tabular}

Source: Authors' calculations.

a. Totals may not add because of rounding.

percentage point average overprediction during 1976:3-1979:3 therefore resulted in part from some offsetting of structural disturbances, but the chief implication of this decomposition is that all disturbances were small (in absolute value) on average. In short, the forecast for 1979:3 through 1976:3 was right for the right reason.

By contrast, the -0.72 percentage point mean underprediction of the bill rate for 1979:4-1983:2 was much more the result of large structural disturbances offsetting one another. The main factors at work here were an average positive disturbance to price inflation and a large average negative disturbance to money supply growth, which raised the bill rate by 3.98 points and 2.69 points, respectively. Largely offsetting these effects was a large average positive disturbance to the yield-spread relation, which lowered the bill rate by 5.17 points.

\section{Elements in the Decomposition}

The model's average forecast of the short-term interest rate for the period since October 1979 contains a large element of being right (or at least not dramatically wrong) for the wrong reason. Three phenomenaan average positive disturbance to price inflation, an average negative disturbance to money supply growth, and an average positive disturbance to the yield spread-came close to offsetting one another. Each of these three large average disturbances merits separate consideration.

First, the average positive disturbance to the price-setting relation indicates that since October 1979 price inflation has decelerated even 
more sluggishly than would have been consistent with the relevant historical experience. ${ }^{12}$ Because of the simple specification of the price (aggregate supply) equation as shown in table 1, the only elements of that historical experience that matter in this context are real economic activity, the terms of trade, and the force of inertia as represented by past inflation rates. A positive disturbance on average during 1979:41983:2 therefore means that, given the actual magnitude of the 1980 and 1981-82 business recessions and the appreciation of the dollar's international exchange rate during this period (and given the actual inflation rate in 1979:3), a replication of historical experience would have called for a greater slowing of inflation than actually occurred. Because prices continued to rise more rapidly than predicted, however, so too did nominal money demand. Given the growth of the nominal money supply, short-term interest rates were accordingly higher.

The finding that inflation since October 1979 slowed less than the model predicted has implications that go well beyond the specific context of this paper. Much of the debate about the effectiveness of monetary policy in recent years has focused precisely on the question of whether previous historical experience would be adequate to characterize the response of price inflation following an announced change in monetary policy regime like that implemented in October 1979. The claim in question, however, has been that prices would respond to an announced and implemented slowing of money growth by decelerating more quickly than the previous experience implied. Such a claim would be important, if true, because then slower growth of the nominal money stock need not imply so much (in the extreme, any) slower growth of real balances, and hence need not imply so much (any) slower growth of real economic activity. In short, if it had been more rapid than historical experience predicted, disinflation would have been less costly than that experience suggested. ${ }^{13}$

12. This result is parallel to Perry's finding, presented in another paper in this issue, that the change in policy did not produce unexpectedly quick disinflation; see George L. Perry's paper in this issue, "What Have We Learned about Disinflation?"

13. For a discussion of these issues, see Benjamin M. Friedman, "Recent Perspectives in and on Macroeconomics," Working Paper 1208 (National Bureau of Economic Research, 1983). In some more recent forms of this argument, a coordinated fiscal policy is also necessary for this result; see, for example, Thomas J. Sargent and Neil Wallace, "Some Unpleasant Monetarist Arithmetic," Federal Reserve Bank of Minneapolis, Quarterly Review, vol. 5 (Fall 1981), pp. 1-17. 
The finding in this paper, however, is just the opposite. The experience of price inflation since 1979 has indeed differed from what would have been expected from the severe double business recession and the sharp exchange rate appreciation on the basis of earlier correlations, but that difference has been an even slower deceleration of prices than conventional estimates had implied. Each percentage point of disinflation has therefore been not less but more costly than conventional estimates predicted.

Second, the average negative disturbance to the growth of money supply is presumably the sign of a more restrictive monetary policythough not in so obvious or straightforward a way as it may first appear. Because the sharp break in interest rate behavior that occurred between the third and fourth quarters of 1979 corresponded almost exactly to the Federal Reserve System's announcement of new monetary policy operating procedures, it is not surprising to find a negative disturbance to money supply standing out as a key factor in the model's underprediction of short-term interest rates since then. Indeed, a major theme in discussions of the subsequent high interest rates in the United States has been the role of monetary policy.

The most familiar argument along these lines has been that the Federal Reserve in October 1979 adopted not just new procedures but, more importantly, a new anti-inflationary policy orientation. According to this view, the subsequent unprecedentedly high short-term interest rates have simply reflected an unprecedentedly tight monetary policy, corresponding to substantially slower growth of the major monetary aggregates than would otherwise have taken place. An alternative argument with the same conclusion is that the increased interest rate volatility brought about by the Federal Reserve's new operating procedures has stimulated the demand for money, and hence raised interest rates for a given money supply. ${ }^{14}$ Other variants are also possible.

The model employed here is capable of addressing some aspects of this question. The model treats the money supply as jointly determined

14. It seems more plausible a priori to consider the greater interest rate volatility a cause of higher levels of long-term interest rates but not short-term rates, in that asset price volatility probably increases the demand not just for money but also for relatively stable-price assets like Treasury bills. For an argument that volatility raises both long- and short-term interest rates, see Angelo Mascaro and Allan H. Meltzer, "Long- and ShortTerm Interest Rates in a Risky World," Journal of Monetary Economics, vol. 12 (November 1983), pp. 485-518. 
by the nonbank public's demand for money balances and by the banking system's willingness to supply money balances, represented by an equation that takes the growth of nonborrowed reserves (and the discount rate) as given. To the extent that some change in the Federal Reserve's policy orientation altered the quarter-to-quarter supply of nonborrowed reserves, in principle the model should be able to incorporate that change into its forecast of money supply, and hence of short-term interest rates and other variables. If nothing had changed except the behavior of reserves (and if the model's equations were sufficiently accurate), the model should not have overpredicted the nominal money supply, and hence underpredicted short-term interest rates, as shown in table 2.

The results presented above therefore suggest that the source of the high short-term interest rate levels prevailing since October 1979 has not been so simple as a change in monetary policy that can be adequately summarized by the movement of nonborrowed reserves. Instead, over a time horizon as long as fifteen calendar quarters the Federal Reserve presumably adapts its provision of reserves to take account of the growth of the money stock in relation to the corresponding money growth target, so that the actual monetary policy variable over this period would more plausibly be the money supply itself rather than the supply of nonborrowed reserves as in the model. As the decomposition in table 2 shows, if the dynamic simulation of the model had taken the actual values of the nominal money supply for 1979:4-1983:2 as given instead of determining them endogenously in the simulation, the resulting forecast of the Treasury bill rate would have been 2.69 percentage points higher on average during the period. ${ }^{15}$ To the extent that growth of the money stock itself was the Federal Reserve's monetary policy variable during this period, the results suggest that tighter monetary policy-in the sense of a slower monetary growth than would have been consistent with

15. Because of the use of simultaneous equations methods to estimate the model, simulating the model with a variable modeled as endogenous but taken as exogenous for purposes of the simulation is in general not the same as treating that variable as exogenous from the outset. An alternative approach to addressing the issues raised here in connection with monetary policy would be to introduce a "monetary policy reaction function" to explain the growth of the money supply in terms of macroeconomic variables, like inflation and the growth of real output, which the Federal Reserve presumably takes into account in choosing its money growth targets. In the context of a model constrained to be so small and simple as the one used here, however, it would be difficult to identify such a money supply function separately from money demand. 
Table 3. Decomposition of Long-Term Interest Rate Forecast Errors, 1976:3-1983:2a Percent

\begin{tabular}{lcc}
\hline $\begin{array}{c}\text { Error and } \\
\text { decomposition }\end{array}$ & $\begin{array}{c}\text { Mean, } \\
\text { 1976:3-1979:3 }\end{array}$ & $\begin{array}{c}\text { Mean, } \\
\text { 1979:4-1983:2 }\end{array}$ \\
\hline Forecast & 9.77 & 10.32 \\
Actual & 9.51 & 14.81 \\
Error source & 0.26 & -4.49 \\
Aggregate demand & 0.00 & 0.12 \\
Aggregate supply & -0.36 & -0.92 \\
Money demand & 0.36 & 0.12 \\
Money supply & 0.38 & -0.92 \\
Term structure & -0.12 & -2.89 \\
\hline
\end{tabular}

Source: Authors' calculations.

a. Totals may not add because of rounding.

previous experience, given the prevailing conditions-raised the average short-term interest rate almost 3 percentage points higher after October 1979.

Two factors, then, sluggish deceleration of price inflation and slow growth of the nominal money supply, contributed greatly to the high level of short-term interest rates during 1979:4-1983:2 in ways that the model did not predict. At the same time, the shift in the yield-spread relation, which failed to predict the high level of long-term interest rates, contributed more than 5 percentage points on average in the opposite direction. ${ }^{16}$

This quantitatively important impact of the yield-spread disturbance in mitigating the model's underprediction of short-term interest rates during 1979:4-1983:2 is not surprising in light of the well-known inadequacy of the single-equation unrestricted reduced-form approach to modeling the term structure of interest rates. ${ }^{17}$ Table 3 presents a summary of the respective forecasts of the bond rate generated by the 1976:3-1979:3 and 1979:4-1983:2 dynamic simulations of the model, together with the associated error decompositions, in a form analogous

16. In addition, as table 2 shows, the change in the mean aggregate demand disturbance offset another 0.66 percentage point. The change in the mean money demand disturbance was negligible.

17. See, for example, Benjamin M. Friedman, "The Determination of Long-Term Interest Rates: Implications for Fiscal and Monetary Policies," Journal of Money, Credit and Banking, vol. 12 (May 1980), pp. 331-52; and Friedman and V. Vance Roley, "Models of Long-Term Interest Rate Determination," Journal of Portfolio Management, vol. 6 (Spring 1980), pp. 35-45. 
to those shown for the Treasury bill rate in table 2 . For all practical purposes the model misses entirely the more than 5 percentage points average rise in the bond rate between these two periods. This failure is more striking because the model, as previously noted, does successfully predict 3.80 points of the corresponding 4.82 points average increase in the bill rate, while the bill rate is the only other jointly determined variable included in the model's simple term-structure equation. ${ }^{18}$ This failure is not due to the especially compact form of this model's termstructure equation, with its use of a rational distributed lag to capture the relation between long- and short-term rates. Other researchers, using more elaborate and carefully constructed term-structure equations, have reported essentially equivalent results for this period. ${ }^{19}$

This failure of the model's term-structure equation (a "disturbance" to that equation, in terms of the formal analysis) caused the model to predict higher short-term interest rate levels in 1979:4-1983:2 than it would have forecast on the basis of an accurate prediction of long-term rates. Underpredicting the bond rate leads, by way of the aggregate demand equation, to overpredicting real economic growth. Overpredicting real growth leads, in turn, via the money demand equation, to overpredicting the growth of demand for real balances at any given level of the bill rate. Overpredicting real growth also leads, by way of the aggregate supply equation, to overpredicting price inflation, and hence to underpredicting the growth of the supply of real balances for a given growth of the nominal money supply. Overpredicting the demand for real balances while underpredicting the corresponding supply leads, of course, to overpredicting the bill rate. As the decomposition in table 2 shows, if the dynamic simulation of the model had taken the actual

18. Because they lower the short-term interest rate prediction, both the aggregate supply disturbance and the money supply disturbance do contribute just under 1 percentage point each on average toward underprediction of the long-term rate during 1979:4-1983:2. The nearly accurate prediction of the Treasury bill rate makes the large underprediction of the bond rate all the more surprising here in that, because of the model's logarithmic specification, the intercept is in effect a multiplicative term premium.

19. See, for example, Robert J. Shiller, John Y. Campbell, and Kermit L. Schoenholtz, "Forward Rates and Future Policy: Interpreting the Term Structure of Interest Rates," $B P E A, 1: 1983,173-217$. The results they report in table 2 of that paper for their standard equation closely resemble those summarized in table 3 here. In general, any change either in the time-series properties of the short-term rate or in the determinants of risk or term premiums will change the behavior of the long-term rate in comparison with that predicted by a historically estimated term-structure equation. 
1979:4-1983:2 values of the long-term interest rate as given instead of determining them endogenously, the resulting forecast of the short-term interest rate would have been 5.17 points lower on average during this period. ${ }^{20}$

In sum, the model's relatively successful prediction of the increase in the average level of short-term interest rates after October 1979 is, in large part, a case of being right for the wrong reason. Disturbances in three of the model's five equations were, on average, large but offsetting. Disturbances to price setting and to money supply growth both contributed to making short-term interest rates higher than historical experience would have suggested, and hence both contributed toward underpredicting short-term rates. A disturbance to the yield-spread relationthat is, a failure of the model's term-structure equation-had the reverse effect, resulting in a fairly accurate forecast overall.

\section{Real Interest Rates and Aggregate Demand}

One potentially worrisome drawback of this analysis is that the model used to generate the forecasts of short-term interest rates reported in table 1 does not explicitly include real interest rates as a determinant of aggregate demand. Instead, as equation 1 shows, the model's aggregate demand equation relates real spending to a nominal interest rate, thereby implicitly admitting some combination of real and nominal rate effects without explicitly distinguishing either. It is possible, therefore, that the model's underprediction of short-term interest rates after October 1979 is somehow due to the omission of an explicit real interest rate from the aggregate demand equation. It turns out, however, that this is not the case.

Table 4 presents an alternative short-term interest rate forecast based on a five-equation version of the model that differs from the original used above because it includes a distributed lag of ex post real short-term interest rates as a determinant of real spending and therefore excludes the original model's term-structure equation. The ex post real shortterm rate is simply the nominal short-term rate minus the annualized percentage change in the GNP price deflator. Although a long-term interest rate would be more plausible on a priori grounds, the correspon-

20. The first point made in note 15 is relevant here also. 
Table 4. Short-term Interest Rate Forecasts and Forecast Errors, Alternative Model, 1979:4-1983:2

Percent

\begin{tabular}{rrrrrrrr}
\hline & \multicolumn{3}{c}{ Nominal rate } & & 3 & Real rate \\
\cline { 2 - 4 } \cline { 6 - 7 } Quarter & Forecast & Actual & Error & & Forecast & Actual & Error \\
\hline $1979: 4$ & 10.83 & 11.80 & -0.97 & & 2.28 & 4.77 & -2.48 \\
$1980: 1$ & 11.45 & 13.46 & -2.01 & & 2.38 & 4.31 & -1.93 \\
2 & 10.97 & 10.05 & 0.92 & & 1.79 & -0.33 & 2.12 \\
3 & 9.11 & 9.24 & -0.13 & & 0.34 & 0.76 & -0.42 \\
4 & 9.79 & 13.71 & -3.92 & & 1.74 & 3.00 & -1.26 \\
$1981: 1$ & 9.34 & 14.37 & -5.02 & & 1.99 & 4.34 & -2.35 \\
2 & 9.46 & 14.83 & -5.37 & & 2.50 & 9.12 & -6.62 \\
3 & 9.00 & 15.09 & -6.09 & & 2.75 & 6.09 & -3.34 \\
4 & 8.14 & 12.02 & -3.88 & & 2.96 & 3.42 & -0.47 \\
$1982: 1$ & 8.36 & 12.90 & -4.54 & & 3.44 & 8.66 & -5.22 \\
2 & 7.74 & 12.36 & -4.62 & & 3.48 & 6.91 & -3.43 \\
3 & 6.67 & 9.71 & -3.03 & & 3.17 & 6.07 & -2.90 \\
4 & 6.00 & 7.94 & -1.94 & & 1.69 & 4.16 & -2.48 \\
$1983: 1$ & 6.12 & 8.08 & -1.96 & & 2.05 & 2.73 & -0.68 \\
2 & 6.04 & 8.42 & -2.38 & & 2.92 & 4.99 & -2.08 \\
Mean & 8.60 & 11.60 & -3.00 & & 2.36 & 4.60 & -2.24 \\
\hline
\end{tabular}

Source: Text equations 1a, 2-4, 6, estimated over 1961:1-1979:3.

dence between any measurable ex post real rate and the relevant ex ante rate would be highly problematical for a long-term rate.

The aggregate demand equation in this alternative model, estimated as before but with 1961:1-1979:3 data, is

$$
\begin{aligned}
\Delta X_{t}= & 0.0056+0.0003 i_{t-1}-0.0004 i_{t-2} \\
& (3.8) \quad(0.4) \quad(-0.5) \\
& +0.0010 i_{t-3}-0.0010 i_{t-4}+0.4917 \Delta X_{t-1} \\
& (1.2) \quad(-1.4) \quad(5.4) \\
& +0.0974 \Delta E_{t}-0.0996 \Delta I_{t-1} \\
& (1.8) \quad(-3.0) \\
\bar{R}^{2}= & 0.43, \text { standard error }=0.00835, \text { rho }=-0.3,
\end{aligned}
$$

where $i_{t}$ is the ex post real Treasury bill rate $\left(r_{S t}-4 \Delta P_{t}\right)$, and the numbers in parentheses are $t$-statistics. The use of a distributed lag of ex post real-rate values follows the finding in the empirical investment literature that changes in the service price of capital, of which the real interest rate is a major component, have their major influence on 
investment spending only after several quarters. ${ }^{21}$ Nevertheless, the estimated semielasticity of real spending growth for the real Treasury bill rate is small during 1961:1-1979:3. In particular, the equation implies that an increase of 1 percentage point in the real Treasury bill rate reduces the growth of real spending by only one-tenth of 1 percent. ${ }^{22}$

Table 4 shows the resulting performance of the five-equation model in forecasting both nominal and real short-term interest rates during 1979:4-1983:2. Like the forecasts reported in table 1, these are based on a dynamic simulation in which, after the initial quarter, the forecast of each variable relies on the model's forecast of all endogenous variables in the previous period.

The results shown in table 4 for nominal short-term interest rates differ from those shown in table 1 in the expected way, given the role of the yield-spread disturbance discussed above. The five-equation model underpredicts the nominal rate in all quarters except 1980:2, with a mean error of -3.00 percentage points for the entire fifteen-quarter forecast period. In the absence of the distortion due to the original model's termstructure equation, therefore, the underprediction by the five-equation model of short-term nominal interest rates is about $2 \frac{1 / 4}{4}$ percentage points greater than that of the original model.

The five-equation model also underpredicts ex post real short-term interest rates, with a mean error of -2.24 percentage points. Here again the results differ from those generated by the original six-equation model in the expected way, given the deletion of the term-structure equation. Although no real interest rate explicitly appears in the original model, it is straightforward to calculate that model's forecast of the ex post real short-term interest rate from the corresponding nominal rate and price inflation forecasts. Doing so indicates that the six-equation model underpredicts the ex post real short-term rate during 1979:4-1983:2, but with mean error of only -0.03 percentage point (again due to some large

21. See for example, Peter K. Clark, "Investment in the 1970s: Theory, Performance, and Prediction," BPEA, 1:1979, pp. 73-113.

22. Mishkin has also documented the difficulty in finding significant correlations between the ex post real bill rate and real income growth. He pointed out the difficulty in discerning the movement between real variables and real interest rates in a sample in which there was so little variation in real rates; see Frederic S. Mishkin, "The Real Interest Rate: An Empirical Investigation," in Karl Brunner and Allan H. Meltzer, eds., The Costs and Consequences of Inflation, Carnegie-Rochester Conference Series on Public Policy, vol. 15 (Amsterdam: North-Holland, 1981), pp. 151-200. 
offsetting errors). In the absence of the term-structure equation, the fiveequation model again shows an underprediction about $2 \frac{1 / 4}{4}$ points greater than that of the original model.

Overall, this correspondence between the respective results of the six-equation model and the alternative five-equation model suggests that the conclusion that short-term interest rates have been "too high" since October 1979 does not hinge in any important way on the use of a nominal interest rate in the aggregate demand equation of the original six-equation model.

\section{A Caveat on Structural Change}

The analysis summarized in table 2 decomposes the errors made in forecasting short-term interest rates after 1976:2 or 1979:3 into components attributed to the additive disturbance terms in the underlying model's structural equations. As the discussion at the outset has already noted, this analysis is conditional on the invariance of the model's parameters to any changes in the relevant economic environment that may have occurred after 1976:2 or 1979:3, respectively. Especially in the context of the change in the Federal Reserve System's monetary policy procedures (and perhaps also its policy orientation) announced at the beginning of October 1979, this invariance assumption merits closer inspection.

If a structural break did occur in October 1979, it would not be appropriate to use the model's historically estimated parameters to recover from the model's forecast errors the disturbances corresponding to each equation. Nevertheless, even in the presence of such a break, it is still possible - and potentially valuable-to compare the recent behavior of short-term interest rates to the forecast implied by the historically estimated model. Such a comparison can still determine whether the behavior of short-term rates has been unusual in light of the historical correlations among key macroeconomic aggregates as summarized by the model.

As is clear in table 1, the model's post-1979:3 errors in predicting short-term interest rates differ in both sign and magnitude from their post-1976:2 equivalents. An alternative interpretation of this result to the one offered above is that shifts in the slope parameters of the 
Table 5. F-Statistics for Tests of Changes in Parameters, Selected Periods

\begin{tabular}{lccc}
\hline Equation & $\begin{array}{c}\text { Break at } \\
1976: 2\end{array}$ & $\begin{array}{c}\text { Break at } \\
1979: 3\end{array}$ & $\begin{array}{c}\text { Break at } \\
1979: 3 \\
\text { (slopes } \text { only) }\end{array}$ \\
\hline Aggregate demand & 1.17 & $5.14^{*}$ & $3.78^{*}$ \\
Aggregate supply & 1.28 & $2.46^{*}$ & $1.99^{* *}$ \\
Money demand & 0.26 & $6.89^{*}$ & $3.24^{*}$ \\
Money supply & 1.11 & $8.53^{*}$ & $7.92^{*}$ \\
Term structure & 0.37 & $3.87^{*}$ & $3.53^{*}$ \\
\hline
\end{tabular}

Source: Authors' calculations.

* Significant at 1 percent level.

** Significant at 5 percent level.

estimated behavioral equations, not just additive distrubances, accounted for this sharp difference. Whether or not the parameters of the model are invariant to changes in the behavior of monetary policy-or, for that matter, to any other change-is an empirical issue. In contrast to the absence of any evidence of a break after 1976:2 as discussed above, the results of Chow tests reported in table 5 indicate statistically significant evidence of a break after 1979:3 for each of the five estimated equations. Moreover, as that table also shows, the results of Chow tests for stability of the slope parameters (that is, a Chow test for each equation including an intercept shift after 1979:3) also indicate a break for each of the five equations.

These findings reinforce the impression, given in a more specific way by the post-1979:3 underprediction of short-term interest rates, that the relevant correlations among major macroeconomic quantities and prices in fact did not remain invariant to the October 1979 shift in monetary policy regime. ${ }^{23}$ This result is not surprising on a priori grounds. Expectations of future monetary policy behavior are presumably important determinants of macroeconomic behavior, yet the simple specifications in the model used here omit such expectational effects. The aggregate supply and term-structure relations are obvious examples, but the other equations may be affected as well. For example, changes in monetary policy behavior such as the changes in operating procedures implemented in October 1979 in general change the variance-covariance structure of asset returns, and changes in stochastic asset-return struc-

23. As Sims has pointed out in a different context, however, it remains difficult to distinguish a "structural" break from the effect of outlier residuals; see Christopher A. Sims, "Macroeconomics and Reality," Econometrica, vol. 48 (January 1980), pp. 1-48. 
tures presumably affect the portfolio behavior that underlies the determination of both short- and long-term interest rates. ${ }^{24}$ Moreover, this problem is hardly a feature associated only with simple models like this one. More sophisticated rational expectations econometric models are also not invariant to changes like those that alter asset return variancecovariance structures. ${ }^{25}$

Even so, it is important to recall that the shift in aggregate supply behavior since October 1979 reported here was in the opposite direction of that implied by familiar claims about the effects of announced changes in monetary policy. What was surprising about the course of prices in 1979:4-1983:2 was how slowly, not how rapidly, they decelerated.

In sum, the problem of changing slope parameters is at least potentially important here. Its implication is certainly to warrant caution, perhaps even a healthy skepticism, in accepting the results of the error decompositions presented above. The more basic finding remains in any case: since October 1979, short-term interest rates have been high in comparison with the implications of previous historical correlations.

\section{Conclusions}

Two questions motivated the analysis in this paper: (1) Have shortterm interest rates in the United States recently been "too high" in some meaningful sense? (2) If so, why?

The paper's answer to the first question is yes. Given the relevant historical relations among interest rates and other key aspects of macroeconomic activity, U.S. short-term interest rates since October 1979 have been higher than would have been predicted. Moreover, although the specific model used to summarize those historical relations imposes

24. For evidence that the greater interest rate volatility resulting from the new operating procedures changed borrowing behavior in a way that could account for the breakdown of the term-structure equation discussed above, see Benjamin M. Friedman, "Federal Reserve Policy, Interest Rate Volatility, and the U.S. Capital Raising Mechanism," Journal of Money, Credit and Banking, vol. 14 (November 1982), pp. 721-45. For an argument that this greater interest rate volatility changed the interest elasticity of money demand see Carl E. Walsh, "The Demand for Money under Uncertainty and the Role of Monetary Policy" (Princeton University, 1981).

25. See, for example, John B. Taylor, "Estimation and Control of a Macroeconomic Model with Rational Expectations," Econometrica, vol. 47 (September 1979), pp. 126786; and Olivier Jean Blanchard, "The Monetary Mechanism in the Light of Rational Expectations," in Stanley Fischer, ed., Rational Expectations and Economic Policy (University of Chicago Press, 1980), pp. 75-106. 
strong restrictions, there is reason to believe that this result is robust to the presence or absence of those restrictions. Other attempts to address this question with much weaker restrictions on the relevant historical correlations give much the same answer. ${ }^{26}$

The paper's answer to the second question is a specific rendering of the basic story of high demand for real money balances interacting with low supply. In the period since October 1979, price inflation was faster and nominal money growth slower than would have been expected on the basis of previous historical experience, given the values of real output, the terms of trade, and other relevant variables describing macroeconomic conditions. One phenomenon reflected the behavior of the economy's private sector; the other, monetary policy. ${ }^{27}$ The interaction of the two would be expected to raise the level of short-term interest rates, not just in this model but in any familiar representation of interest rate determination. The analysis suggests that it did so by a large amount.

APPENDIX

\section{Extended-Sample Equations of the Pirandello Model}

THE following equations are for the 1961:1-1979:3 sample period. ${ }^{28}$ Aggregate demand:

$$
\begin{aligned}
\Delta X_{t}= & 0.0064-0.1026 \Delta r_{L t}+0.1024 \Delta E_{t} \\
& (4.8) \quad(-2.9) \quad(2.0) \\
& -0.0688 \Delta I_{t-1}+0.4397 \Delta X_{t-1} \\
& (-2.2) \quad(5.0) \\
\bar{R}^{2}= & 0.49, \text { standard error }=0.00780, \text { rho }=-0.4
\end{aligned}
$$

26. See again the parallel analysis based on a vector autoregression system in Clarida and Friedman, "The Behavior of U.S. Short-Term Interest Rates since October 1979." The results of that analysis are also consistent with the conclusion, stated immediately below, connecting the high level of short-term interest rates to the relation between real balances and real economic activity.

27. The conclusion that a change in monetary policy was a large factor in bringing about the high level of short-term interest rates implies neither criticism nor praise. Evaluating the appropriateness of monetary policy during this period lies beyond the scope or intent of this paper.

28. See the text and equations 1 ' through 6 ' for discussion and definitions of symbols. 
Aggregate supply:

$\left(2^{\prime}\right)$

$$
\begin{gathered}
\Delta P_{t}=0.0895 \Delta X_{t-1}+0.0542 \Delta I_{t-1}+0.8700 \Delta P_{t-1} \\
(3.4) \quad(3.9) \quad(25.2) \\
\bar{R}^{2}=0.88, \text { standard error }=0.00347, \text { rho }=-0.1
\end{gathered}
$$

Money demand:

$$
\begin{gathered}
\begin{aligned}
\Delta(M-P)_{t}= & 0.1192 \Delta X_{t}-0.0406 \Delta r_{S t} \\
(1.9) \quad(-3.9) & \\
+ & 0.8703 \Delta(M-P)_{t-1} \\
(7.7) & (0.6) \\
\bar{R}^{2}= & 0.53, \text { standard error }=0.00676, \text { rho }=-0.5 ; \\
\Delta M_{t}= & 0.0034+0.2118 \Delta R_{t-1}+0.0097 \Delta r_{S t} \\
& (2.3) \quad(2.1) \quad 0.7627 \Delta M_{t-1} \\
-0.0234 \Delta r_{D t}+ & (8.6) \\
& (-1.3) \quad 0.00481, \text { rho }=-0.2 ;
\end{aligned}
\end{gathered}
$$

Term structure:

$$
\begin{aligned}
& \Delta r_{L t}=0.0472+0.1441 r_{S t}-0.0579 r_{S, t-1} \\
& \text { (1.4) (1.1) } \quad(-0.5) \\
& +0.1376 \Delta(L-S)_{t-1}+0.9100 r_{L, t-1} \\
& \bar{R}^{2}=0.98, \text { standard error }=0.020 \text {, rho }=0.4 ;
\end{aligned}
$$

Nominal income identity:

$$
\Delta Y_{t}=\Delta X_{t}+\Delta P_{t}
$$




\section{Comments and Discussion}

Jeffrey R. Shafer: Richard Clarida and Benjamin Friedman examine whether short-term interest rates in the United States have been "too high" in the 1980s. They provide an affirmative answer to this question and proceed to ask why. Their explanation is that an upward shift in the demand for money interacted with a more restrictive monetary policy after October 1979. The authors present an interesting empirical analysis, but overreach in claiming that it constitutes very strong evidence for these conclusions. For one thing, the authors' claim that interest rates are too high turns out to mean less than it sounds. And their chain of argument leading from the empirical observations to the conclusion that monetary policy is a principal cause of high interest rates has some weak links. This is not to say that the conclusion is wrong, only that the evidence in the paper is not apt.

Few would quarrel with the statement that U.S. interest rates are high by historical standards, whether one is talking about long-term or shortterm rates, nominal or real. Clarida and Friedman document just how much higher rates have been since the fourth quarter of 1979 than they were earlier. But in addressing the question whether they are too high, different groups of people are asking very different things. Policymakers are asking whether interest rates are where they ought to be given policy goals such as output, employment, inflation, and capital formation, and the trade-offs among these goals involved in adjusting policy instruments to reduce interest rates. Portfolio managers are asking whether the level of rates will be sustained or will interest rates come down soon. Analytical economists are asking whether the level of interest rates is explainable by their models of how the world works and whether their models must be revised or abandoned. 
Clarida and Friedman's work takes mainly the third perspective. They seek to interpret interest rate developments in the context of a model that predates the period of extremely high interest rates. Their conclusions, even where they have the "ring" of policy statements, are more analytical conclusions. They do not follow from any systematic analysis in the paper of what policy goals would be achieved by lower interest rates and what the costs might be. Neither do the conclusions imply anything about the likely future course of interest rates, which would be of interest to market participants.

As a research methodology their approach has more to recommend it. Friedman had set forth a compact model of key macroeconomic relations in 1977. He or anyone else who found this model convincing at that time should be interested in how the model has performed out of sample-especially how well it accounts for the higher interest rates of recent years. One appropriate test is a dynamic out-of-sample simulation of the model using the actual values of exogenous variables. The core of the Clarida and Friedman paper is an analysis of the differences between such a simulation and the actual behavior of the economy.

The simulation accounts remarkably well for the higher level of shortterm interest rates from 1979:4 to 1983:2 compared to the previous thirteen quarters. On the face of it, short-term interest rates have not been unaccountably high, but the authors correctly point out that this performance is deceptive. There are sizable errors in individual equations, which offset one another in their effects on the interest rate forecast. But it seems unbalanced to focus on these errors to the total neglect of what exogenous variables of the model contribute to the story.

The principal empirical finding of the paper is that the decomposition of interest rate forecast errors shows that what the authors call aggregate supply and money supply equations contributed to a large underprediction of interest rates. These errors were largely offset by errors in the opposite direction in the term-structure equation. This is useful diagnostic information for someone who wishes to work with the earlier Friedman model. It suggests that these equations are most crucially in need of revision to provide structural stability if one is primarily concerned about how well the model explains interest rates. Otherwise, on a priori grounds and on the basis of reported test statistics, I would have enough concern about the specification of other equations that I would not know where to begin. Particularly disconcerting features of 
other parts of the model include indiscriminate logarithmic transformation of interest rates, the choice of a fiscal variable, and the use of the long-term nominal interest rate in the aggregate demand equation. Interestingly, Clarida and Friedman felt uncomfortable enough with the last feature to make a half-hearted attempt to find alternatives, while letting stand the equations that the variance decomposition identified as more troublesome.

The authors claim that their error decomposition procedure can be used for more than just diagnosis. They attempt to draw extensive insights from the pattern of errors. I think one should be skeptical of their further claims. Let me mention several of my reservations.

First, the reported Chow tests reject structural stability of the slopes for all equations after 1979:3. The authors argue that this does not invalidate the conclusion that interest rates are high by historical standards. But they would have the reader take more than this from the paper. The estimated slope coefficients are at the heart of the errordecomposition exercise. It is going too far to claim that the results are more than indicative for diagnosing how the model has gone off track.

The apparent instability of the slope parameters also undermines the intuition that the authors seek to attach to their results. What they would have the reader do is interpret the error terms in the money and the aggregate supply equations as the effects of unobserved exogenous developments in the recent period. Implicitly they would have us attribute the errors in the term-structure equation to misspecification and hence view them as statistical artifacts to be set aside. There are no grounds for treating the different errors differently.

Second, even if one had confidence in the error decomposition, one could not extract much information about why the errors occurred. What is not known is whether the reason for large errors in the termstructure equation is a risk premium in long-term interest rates, whether it is because long-run inflationary expectations remain high, whether structural government deficits and investment incentives have raised the long-term real interest rate consistent with high employment and output, or whether there is some other reason. The model might have had something more to say on the deficit issue if it had included highemployment tax receipts, as well as government expenditures, as an exogenous variable.

Third, it is misleading to proceed from the observation that money 
supply errors have been important to the conclusion that monetary policy has been more restrictive. It is clear that the authors were fishing for this result from their choice of 1979:4 to begin the second out-ofsample simulation. This break corresponds closely to the October 6, 1979, announcement of a more determined anti-inflationary monetary policy by the Federal Reserve. There are good grounds for believing that this policy change is an important reason why short-term interest rates have been so high if one accepts the existence of considerable momentum in wage-price dynamics and inflationary expectations. But the timing of the errors in the simulation does not fit this explanation so neatly. Table 2 of the paper shows that a shift from overprediction to underprediction of the short-term interest rate occurred earlier and that very large errors emerged only a year later.

Moreover, in the context of the model, errors in the money supply equation ought not be interpreted as policy changes. The money supply function treats the Federal Reserve policy instruments-the supply of nonborrowed reserves and the discount rate-as exogenous. The behavior of these exogenous variables ought to capture policy changes. The function embodies two behavioral elements that are not closely related to the stance of policy. One element is the multiplier relation between total required reserves and $\mathrm{M} 1-$ a convolution of required reserves, the composition of reservable deposits included in and excluded from $\mathrm{M} 1$, and the relative demand for currency. The other element is banks' demand for net free reserves-excess reserves less discount-window borrowing. Changes in the multiplier relation between required reserves and $\mathrm{M} 1$ are taken into account routinely in open market operations. The behavior of free reserves is relatively unimportant over a period of several years. Therefore, persistent errors in the estimated relation simply are not a measure of a monetary policy shift.

How then might one explain the money supply errors? Many things were happening that caused the relation between reserves and M1 to change. During the 1970 s the reserve base was eroding as banks withdrew from membership in the Federal Reserve System and demand deposits declined relative to currency. The Monetary Control Act and the International Banking Act led to the phased-in application of reserve requirements to a much wider set of institutions beginning in late 1980 but with a phasing down of reserve requirements on member banks. Although the ratio of reserves to M1 has continued to fall, they have 
fallen at a slower rate after 1979. This structural change, coming soon after the beginning date for the simulation, could account for the errors in the money supply equation. The coefficients in the equation may also be biased by common trends in the left-hand-side variables, which would pick up the secular erosion of the reserve base. Overprediction in the postsample period would be the result. Whatever the explanation for this overprediction, it cannot, by itself, be taken to reflect monetary policy.

A final, more general concern about the interpretations suggested for the error decomposition is that it presumes that the respective errors in the various equations are independent of one another. There is nothing in the nature of structural disturbances that requires them to be independent. Indeed, in many circumstances the nature of a model may impose systematic relations among structural disturbances. For example, in a demand system an increase in the error term in the demand for one good must be offset by reduced demands for other goods, or budget constraints will not be satisfied. In the present context one can invent reasons why the disturbances in different equations might be related. Taking the authors' interpretation for the sake of illustration, unusually strong exogenous inflationary pressures could well induce money supply policies that are more restrictive than normal. One would then want to call the apparent aggregate-supply and money-supply disturbances independent causes of high interest rates.

There are many more reasons than I have discussed to take the Clarida and Friedman results lightly. Few are likely to find the model satisfying and therefore would not want to take its pathologies seriously.

Although I have serious reservations about the authors' specific exercise, I believe there is considerable value in their general approach of analyzing macroeconomic issues using a small empirical model and attempting to interpret its forecasting errors using information on variables and developments that are omitted from the model. In the policy community and the financial community, people tend to look at many more things than are included in the authors' model. But without a model framework, they tend to do so in partial and often inconsistent ways. A small, closed model is a useful tool to foster consistent general equilibrium thinking in these circles. The big models are simply beyond comprehension. A small model will always have difficulty with forces and structural changes that were not spelled out in advance-the game 
inevitably becomes one of identifying and interpreting error terms structurally. But the analysis of errors needs to be done with close attention to what is going on at a microeconomic level, and a priori calculations of what shift might be attributable to observable developments, such as changes in reserve requirement regulations, are indispensable to such analysis. The small model user cannot abstract from the complexity of the world, even though the model does.

\section{General Discussion}

Several participants discussed the large underpredictions of longterm interest rates which, as Benjamin Friedman and Richard Clarida stress, were inadequately modeled by the term-structure equation. Stanley Fischer reasoned that the high long-term rates were possibly due to high expected inflation rates, and that inflationary expectations should be modeled explicitly in order to test for this. William Branson observed that the rise in the dollar exchange rate showed that long-term rates were not high because expected inflation was correspondingly high-a situation that should depreciate, or not affect, the exchange rate currently, and should depreciate it through time-but rather the rise represented high current and expected real rates of interest. In turn the high real interest rates are caused by the anticipated structural budget deficits that will require both investment and the trade balance to be squeezed. James Tobin replied that deficits did not provide an adequate explanation because the large rise in long-term rates and the biggest underpredictions from historical term-structure equations occurred in the months immediately following the October 1979 change in Federal Reserve policy. This was long before anyone could foresee the large budget deficits that resulted from President Reagan's 1981 fiscal changes.

Edward Bernstein suggested that financial deregulation contributed to raising the level of interest rates and producing the kind of prediction errors observed by the authors. Before March 1980 the interest rates that commercial banks and thrift institutions paid on time and savings deposits, except large CDs, were subject to ceilings established by the Federal Reserve and other regulatory agencies. Whenever money market rates rose above these ceilings, these institutions were unable to compete freely for loanable funds. As a result, Bernstein argued, the demand for credit by borrowers dependent on loans from commercial banks and 
thrift institutions could not fully affect market rates of interest. With deregulation, commercial banks and thrift institutions can now pay interest on checkable deposits and can bid freely in the market to acquire loanable funds. As a consequence, the interest rates at which the supply of and demand for credit are equated under given monetary and economic conditions are higher now than they would have been under previous regulations.

Robert J. Gordon suggested that financial deregulation could help explain the collapse in velocity during 1982 . That collapse must have contributed to errors in the Friedman-Clarida equations and should help explain the high level of short-term interest rates actually experienced. Gordon argued that if the equations had properly specified the demand for money as depending on the difference between the interest rate on money and on other assets rather than just on the level of some interest rate, the equations would have better captured the effects of financial deregulation and performed more accurately.

Christopher Sims questioned the methodology of the FriedmanClarida model and the interpretation of its results. First, he noted that it was inappropriate to treat variables such as the discount rate as exogenous when, in fact, the discount rate appeared to follow market rates. With a reduced form impact coefficient of about 0.5 , the movement in the discount rate would account for a substantial part of the mean change in short-term rates between the two periods analyzed, even if its estimated effect eventually became much smaller. Its minor impact in the reduced form for the long-term rate might help explain why the change in long rates was forecast so much worse than the change in short rates. Second, he noted that many variables, such as those that might capture changing expectations, were omitted from the model. Sims concluded that, both because of such omissions and because the exogeneity of some variables was doubtful, the authors' structural interpretation of the equation errors was unconvincing. The level of interest rates, for example, may not be caused by the factors that Friedman and Clarida stressed. 